\title{
Design and Simulation of 0.75hp Soft Start AC Water Pump Powered by PV Solar System
}

\author{
Rayyan Azam Khan, Liaquat Ali Khan", Syed Zahid Hussain \\ Department of Mechatronics Engineering, Air University, Pakistan
}

Copyright (C) 2015 by authors, all rights reserved. Authors agree that this article remains permanently open access under the terms of the Creative Commons Attribution License 4.0 International License

\begin{abstract}
Shortage of electricity is one of the main problem in the development of rural areas in Pakistan. Photovoltaic techniques are generally attaining an escalating attention and they're to become very competitive alternative, additionally, environmental issues such as population and global warming impact are attracting experts towards green electricity sources such as solar systems. A standout amongst the most imperative provisions of photovoltaic frameworks is for water pumping, especially in rural areas that have a considerable amount of solar radiation and have no access to national grids. They are generally utilized within household and animals water supplies and small-scale irrigation systems [1]. Water pumping from a PV array is a valid option to pollution-generating diesel and human-powered water pumps. PV-array water pumping can be fulfilled with or without a backup module. With a backup module, energy generated by the sun can be stored in the backup; hence, the application of the water pump can be fulfilled, even to a cloudy day, or at night to operate small loads. The application of photovoltaic is increasing in rural areas due to shortage, unavailability and costly electricity. Solar powered water pumps are commonly used in agriculture and residential level. This designed model deals with solar powered submersible pump. Among many available schemes, it consists of a PV panel, a storing backup, a variable-frequency inverter, a charge controller and induction motor coupled with a water pump. The inverter drives the induction motor, which drives the water pump. To obtain maximumoutput power of the Solar panel, the inverter is operated at variable frequency or soft start to minimize stall current of induction motor [5]. This designed model powers $0.75 \mathrm{hp}$ water pump. Different types of controllers can be used to increase frequency gradually from 0 to $50 \mathrm{~Hz}$ with $5 \mathrm{sec}$ of delay each, thus voltage is controlled from 0 to $220 \mathrm{~V} \mathrm{AC}$.
\end{abstract}

Keywords Solar, Soft Start, Frequency, Photovoltaic

\section{Introduction}

This research project consists of following parts.

1. Photovoltaic Panels

2. Soft Start Inverter

3. Charge controller

4. Battery

5. Pump

Process flow of the project is shown in Figure 1 [4].PV array receives energy from the sunlight and generates electric power, which is fed to induction motor via an inverter [2]. Induction motor is mechanically coupled to the water pump. Solar panels which essentially give DC voltage are used to pump water utilizing induction motor. Because of its reliability, dependability, low value and low maintenance cost; induction motor are utilized as a part of majority of commercial, industrial and other applications.Output requires a variable speed control since the motor requires a soft start and the sun constantly changes its position so power generated by stationary PV cells varies accordingly. Due to different voltage situation, motor don't produce maximum torque in specific supply frequency. Therefore, supplied frequency should be changed to achieve maximum power. A single phase induction motor controller (inverter) was developed to drive the motor with variable frequency from $5 \mathrm{~Hz}$ to $50 \mathrm{~Hz}$.Scalar Control (V/f Control) is utilized as speed control technique for variable frequency drives .In this sort of control instrument (scalar control, v/f Control), the motor is fed with variable frequency Pulse Width Modulation (PWM) signal by using full bridge inverter circuit. PWM signals are generated and controlled by a controller. In this design Arduino UNO R3 is utilized for PWM Generation. 


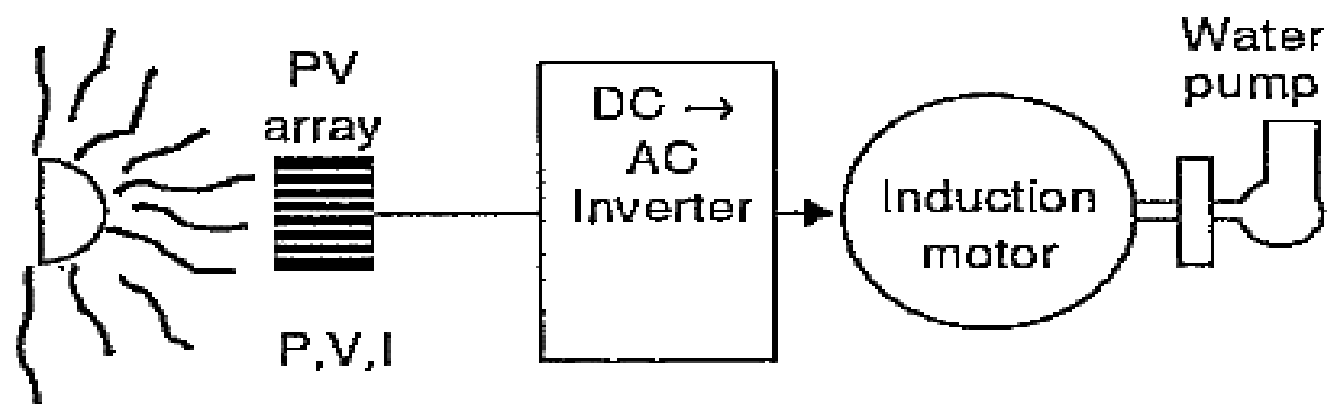

Figure 1. Process flow of the Project [4]

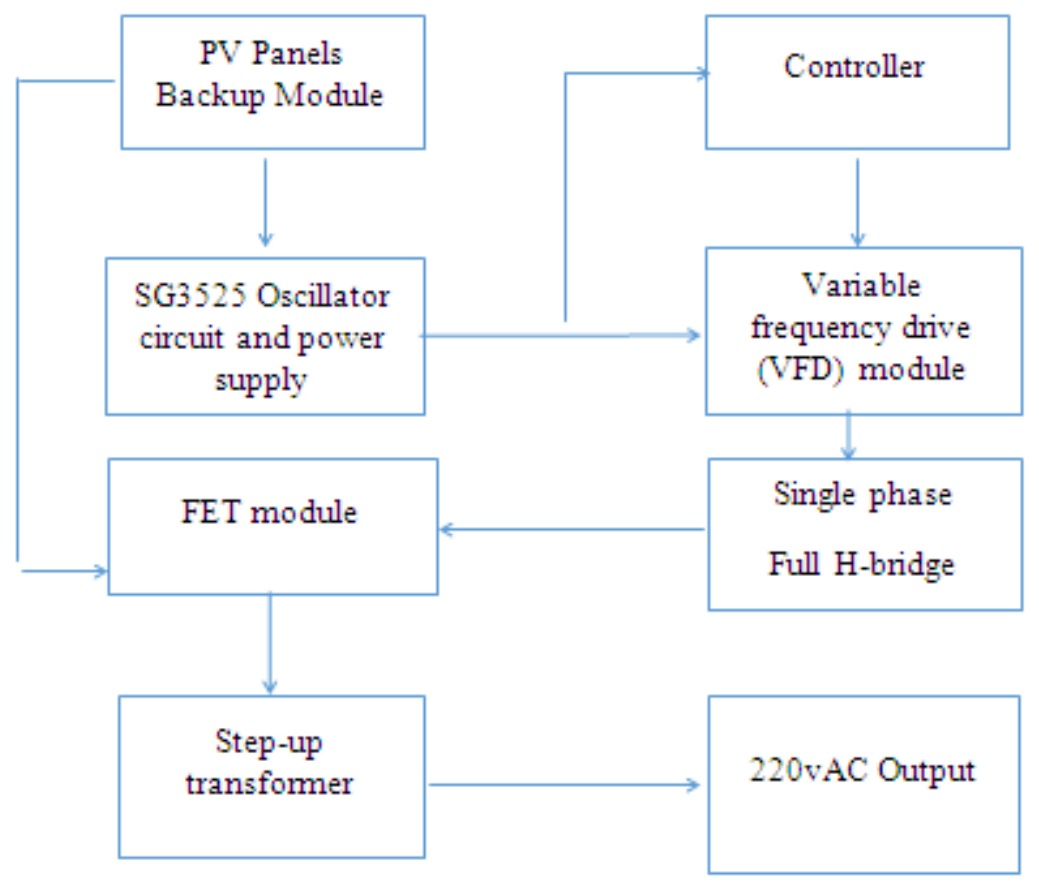

Figure 2. Process flow of Soft Start Inverter

\section{Research Methodology}

Figure 2 shows process flow of soft start inverter .12 Volt DC from battery is given to SG3525 oscillator circuit which converts it into $220 \mathrm{~V}$ AC to power Variable frequency drive (VFD) module. VFD module through Arduino UNO R3 controller is used to control full h-bridge which produces variable frequency $\mathrm{PWM}$ from $5 \mathrm{~Hz}$ to $50 \mathrm{~Hz} .75 \mathrm{~N} 75$ MOSFETs are used because of fast switching speed, high current rating and also economical. The output is then fed into 1200 watt FET module in which six pairs of 75 N75 MOSFETs are connected in parallel to increase wattage, each pair gives 250 watts. In last before output a step-up transformer step up the voltage from $12 \mathrm{v}$ to $220 \mathrm{v}$ AC.

\subsection{VFD Programming Sequence}

Our aim is to decrease stall current so that Submersible pump starts softly. For this purpose we have to decrease voltage. This is obtained by increasing the frequency gradually from $5 \mathrm{~Hz}$ to $50 \mathrm{~Hz}$.To decrease Frequency we will change on and off timeof sine wave. Positive half cycle of $50 \mathrm{~Hz}$ frequency is shown in Figure 3.Table 1 shows the sequence of Voltage and frequency for soft start.

Table 1. Sequence of Voltage and Frequency

\begin{tabular}{|c|c|}
\hline Frequency $(\mathrm{Hz})$ & Voltage $(\mathrm{V})$ \\
\hline 5 & 20 \\
\hline 15 & 60 \\
\hline 25 & 100 \\
\hline 40 & 160 \\
\hline 50 & 220 \\
\hline
\end{tabular}




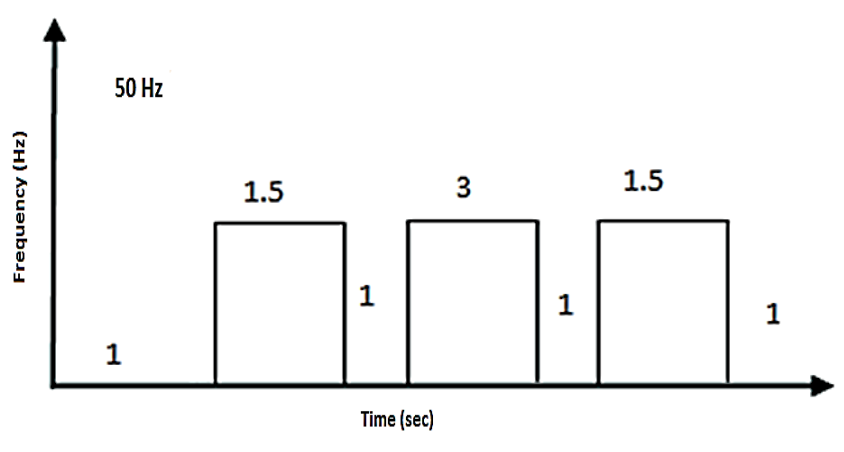

Figure 3. Positive Half Cycle of $50 \mathrm{~Hz}$

\section{Mathematical Modeling of Pump}

While doing the mathematical modeling of the pump we have to come across certain parameters that includes:

i. Total Dynamic Head.

ii. Energy required.

iii. Preliminary design current.

iv. Efficiency of Pump.

\subsubsection{Total Dynamic Head}

Total Dynamic Head (TDH) is the total height of a fluid that is to be pumped, including friction losses in the medium $[6,7]$.

$$
T D H=L_{V}+\lambda_{F F}+F o S
$$

\subsubsection{Hydraulic Energy required}

Equation of the hydraulic energy required for the design[6].

$$
E_{H y d}=\frac{Q_{D r} \cdot T D H}{366.972}
$$

366.972 = Energy conversion factor (Constant derived from water density, force of gravity and time)

\subsubsection{Efficiency of Pump}

The knowledge of required pump rate and TDH allows selection of motor pump and its efficiency assessment [7].

$$
\eta_{\text {pump }}=\frac{T D H \cdot Q_{p} \cdot \frac{1}{E_{H y d}}}{P_{\text {pump }}}
$$

\subsubsection{Preliminary Design Current}

The wire losses are characterized by the adjustment factor which is a $\mathrm{F}_{\mathrm{WL}}$ de-rate factor. The $\mathrm{PV}$ generator preliminary current is expressed by the equation [7].

$$
I_{\text {Desp }}=\frac{1 / E_{H y d} \cdot Q_{D r} \cdot T D H}{\eta_{\text {pump }} \cdot V_{n} \cdot H_{t} \cdot F_{W L}}
$$

\subsection{Mathematical Modeling of Solar Panel}

\subsubsection{Efficiency of PV Array}

The efficiency of the PV array [8].

$$
\eta_{P V}=\frac{V_{m} \cdot I_{m}}{E_{I r r} \cdot A_{p v}}
$$

\subsection{Mathematical Modeling of Battery}

Peukert [11] describes the charging and discharging behavior of batteries.

$$
C_{p}=I^{n} t
$$

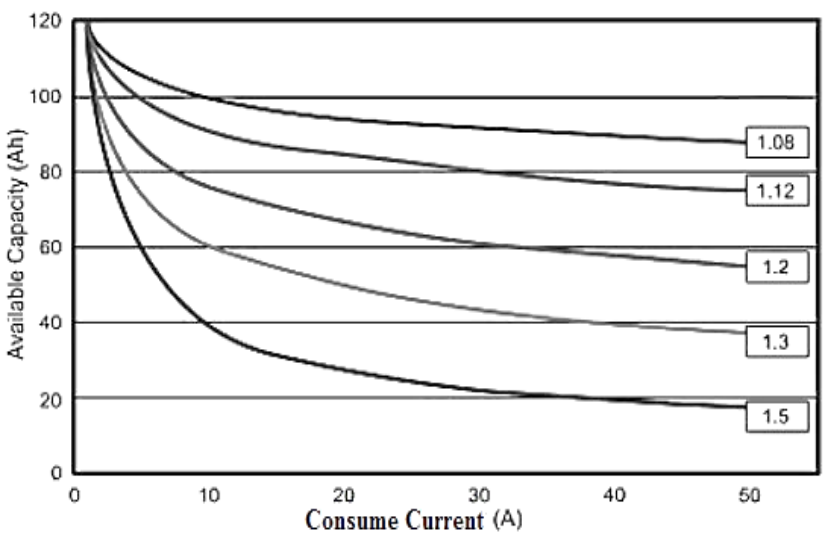

Figure 4. Graph between Available Capacity andConsume Current [11]

Figure 4 shows the dramatic impact of the Peukert's[11] exponent on the available capacity of a 120Ah battery, depending on the ampere draw. Lower the Peukert's[11] Exponent,lesser the effect on available capacity.

In Figure 4, note how the low exponent battery (topmost curve) has more than four times the accessible limit over a high-exponent battery (lowest curve). This graph utilizes a direct scale. The time at which charging of backup starts, the Peukert's[11] role becomes effective. The limit of a backup to store a charge during the bulk phase is also related to its Peukert's[11] exponent.

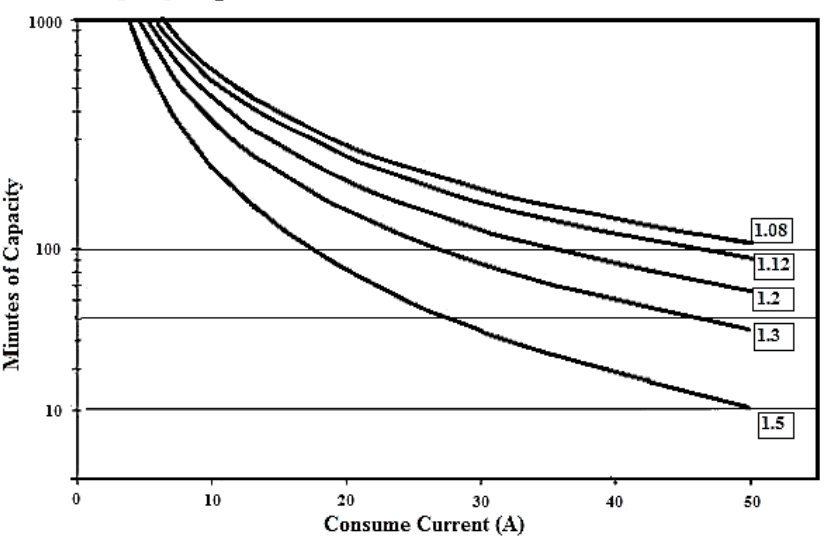

Figure 5. Graph between Reserve Minutes and Consume Current [11]

\subsubsection{Reserve Minutes}

Reserve Minutes are used to calculate time of your backup to withstand a load before its charge has been completely drained out. This calculation is useful for inverters, and other large loads.

In Figure 5 graph shows how backup that have a large Peukert's[11] Exponent will short fall of backup with high 
loads. Here, the low-exponent backup will end up 100 minutes with a 50 amps of load, while the high-exponent backup will end about 20 minutes.

\subsubsection{Charging time of Battery}

Power delivered to Battery

Power delivered to battery by PV panel [3].

$$
P_{d c}=E_{d c} I_{d c}
$$

Time required

Power calculated in Eq (7) gives charging time $h_{0}[3]$.

$$
h_{0} P_{d c}=\text { capacity of battery }
$$

\section{Simulation and Results}

Figure 6 shows the voltage frequency response. As the frequency increases the voltage also increases. This shows that voltage and frequency are directly proportional to each other.

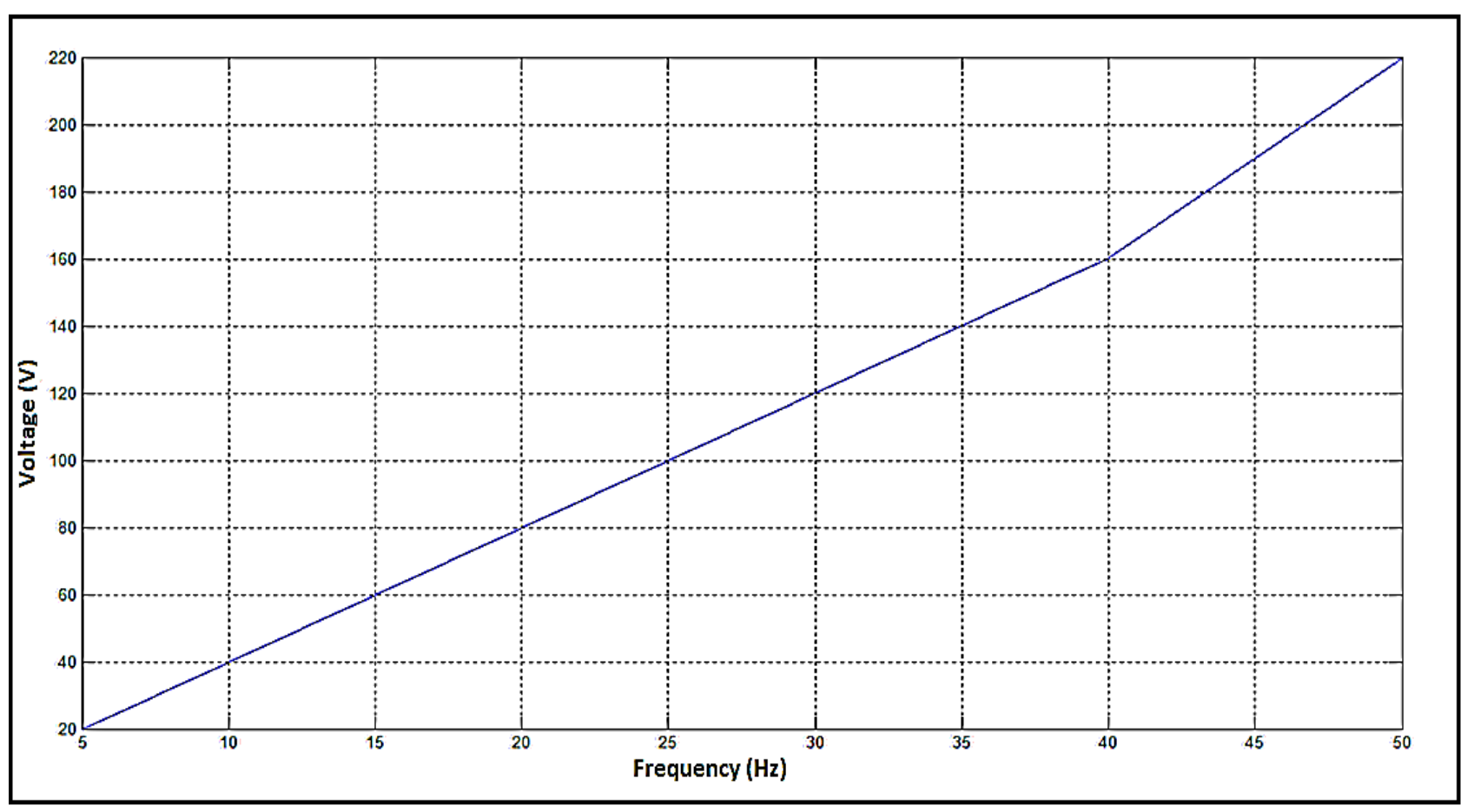

Figure 6. Graph of Voltage and Frequency for Soft Start

\subsection{VFD Output response}

In this simulation desired synchronous frequency and rise time for the motor are given through input buttons attached to Arduino UNO R3 micro-controller and based upon the input commands it generates the PWM and one of the signals which are sent to driver circuit so that switches may be controlled for the proper operation of inverter. The VFD (Variable Frequency Drive) kit response at variable frequencies is given in Figure 7.
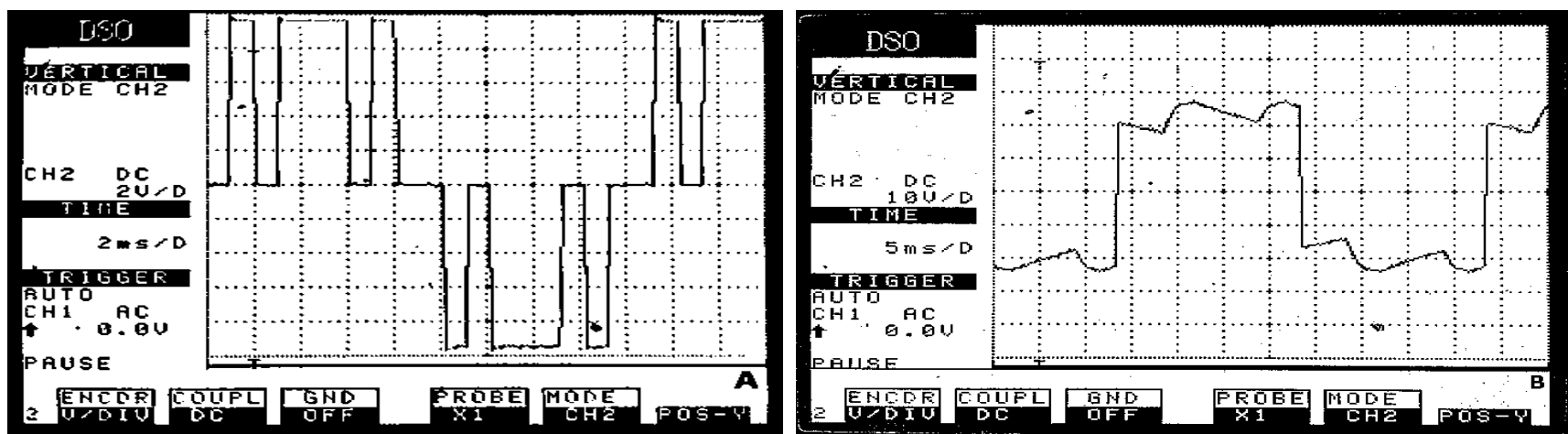

Figure 7. VFD kit response at $20 \mathrm{~Hz}(\mathrm{~A})$ and $50 \mathrm{~Hz}$ (B) 


\subsection{Cost Effective Analysis}

Graph has been plotted between Power and cost to analyze the relationship between them. As the cost increases with increase in Power, The graph is nearly linear as shown in Figure 8.

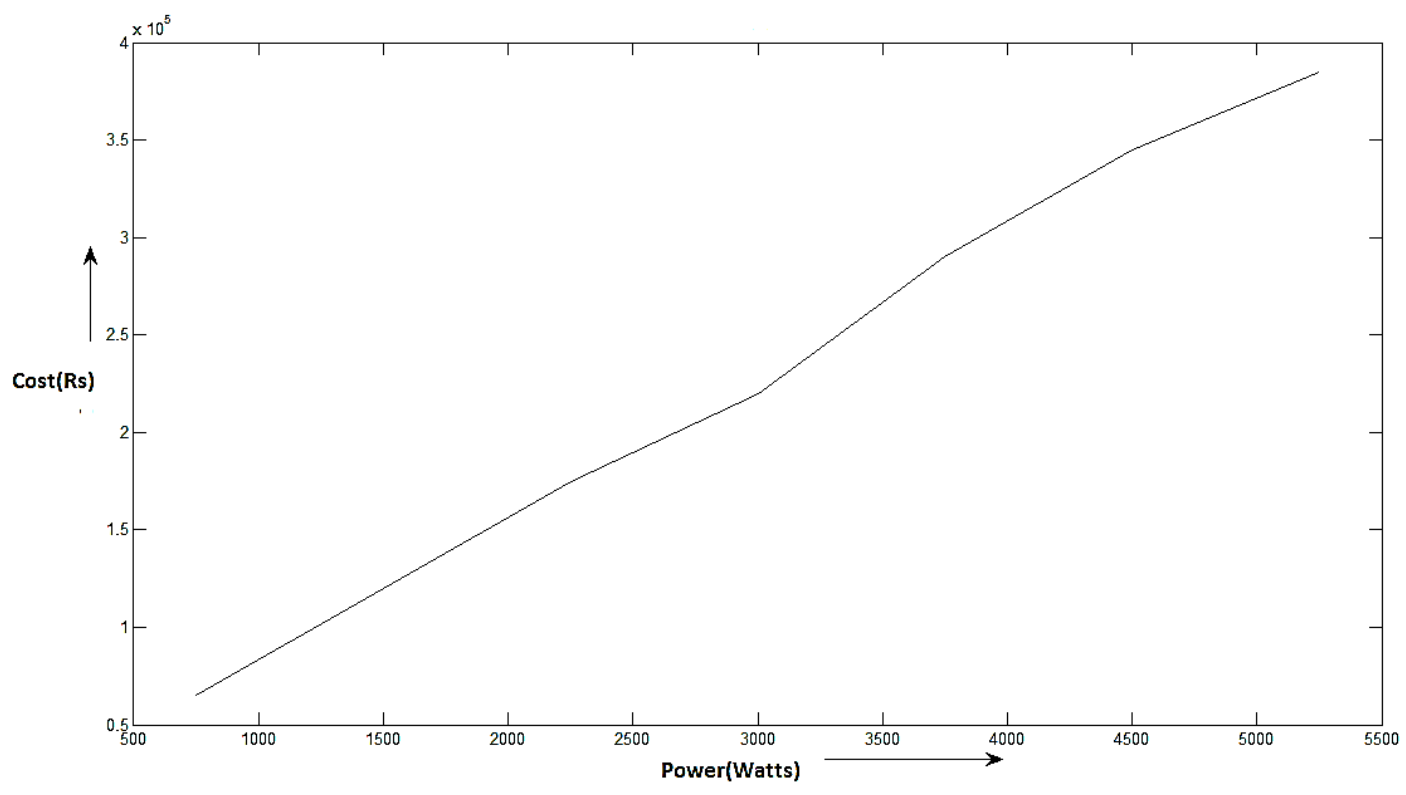

Figure 8. Graph between Power and Cost

The plotted graph between amount of current required for different systems with different Power ratings is linear which is shown in Figure 9.

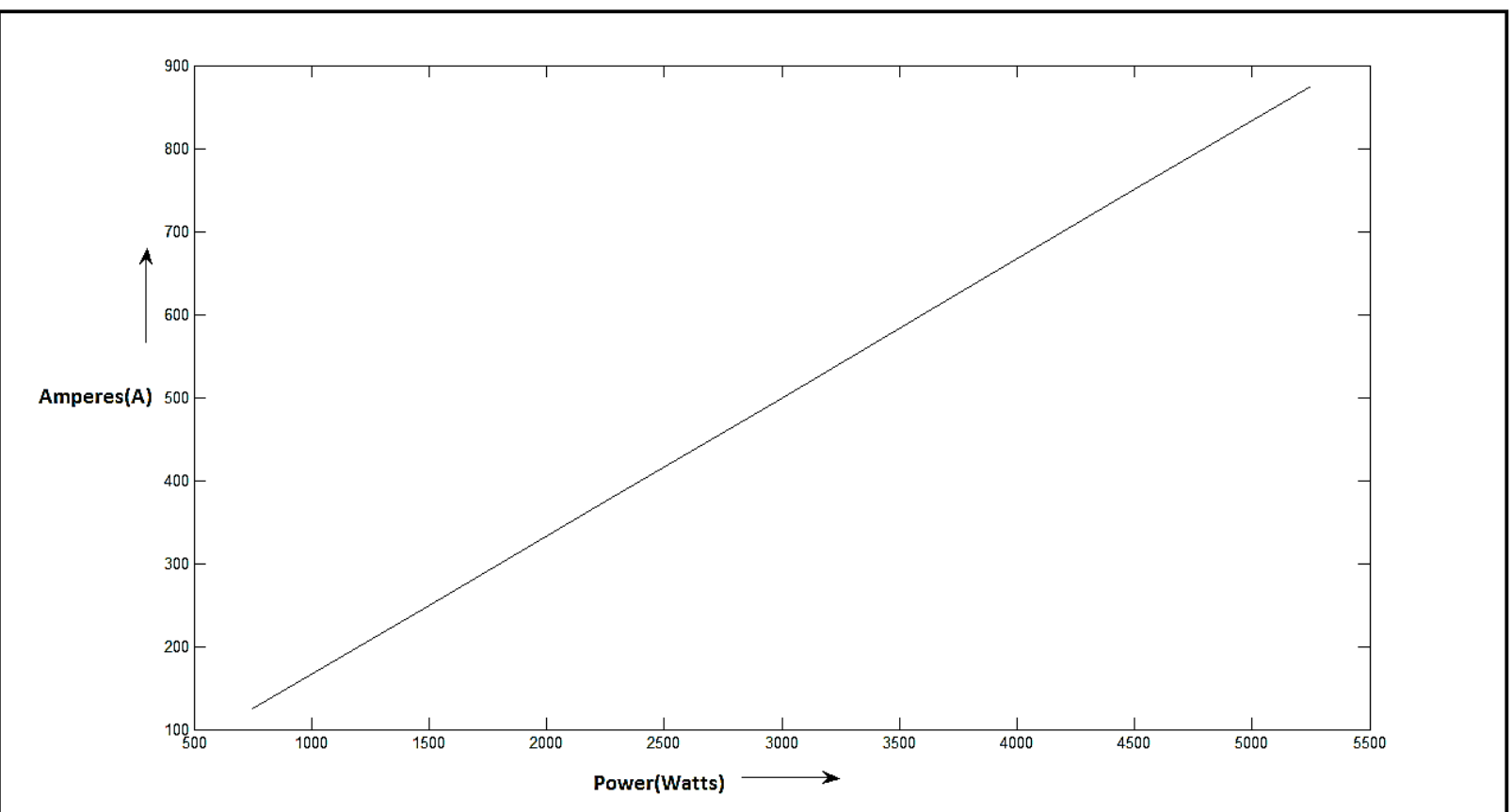

Figure 9. Graph between Power and Current

In market solar panels of different ratings are available such as 150 watt, 180 watt, 200 watt.Cost per watt for each panel varies with rating thus the plotted curve exhibits piecewise-linear property. Different watts of panel available with per watt cost were shown in Figure 10. 


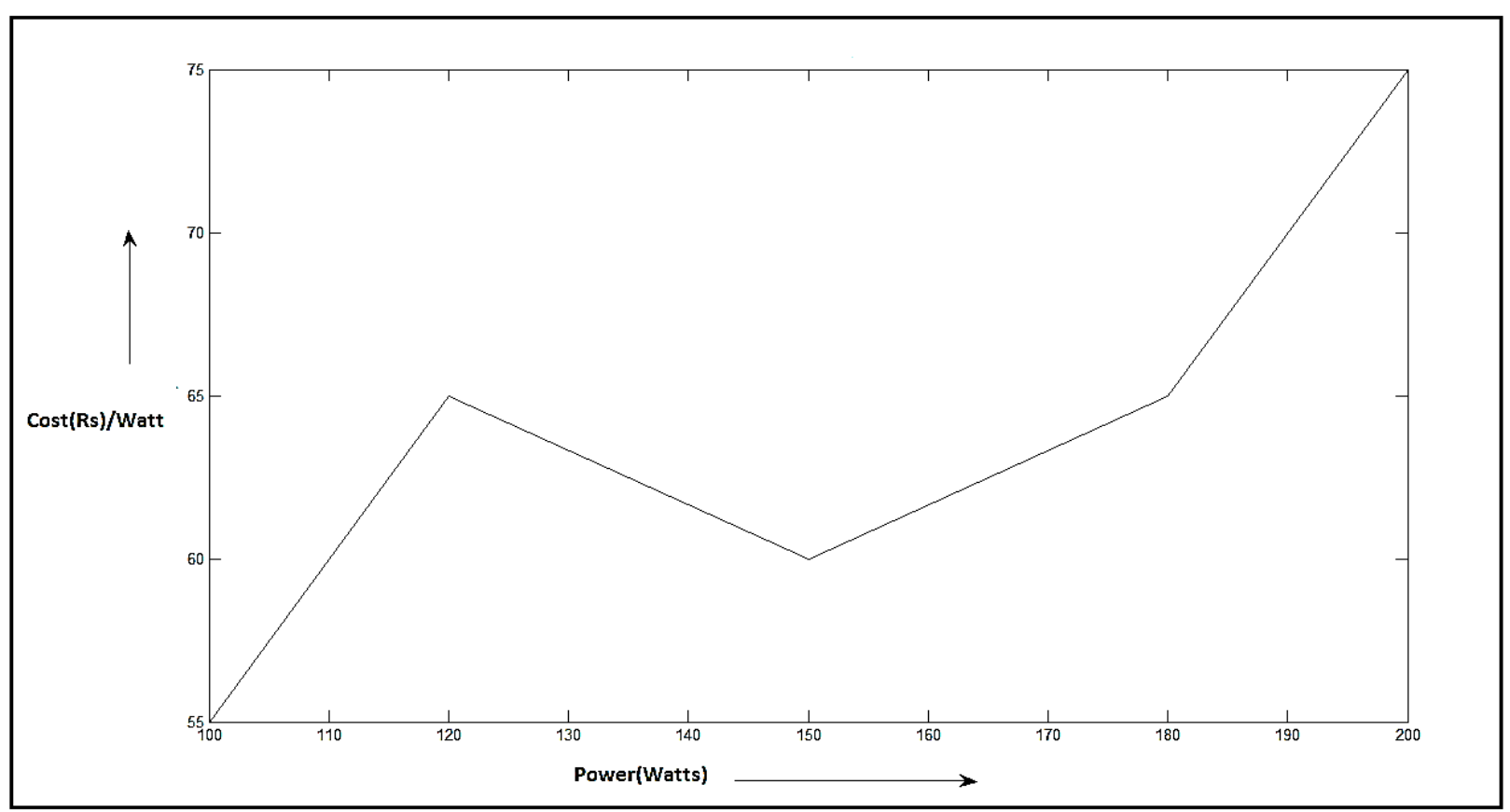

Figure 10. Graph between Power and Cost/watt

\subsection{Annual Solar Energy Output}

The formula globally used to estimate the electricity generated by photovoltaic system [9].

$$
E=A \times r \times H \times P R
$$

\subsubsection{Monthly PV Power}

By monthly radiations falling on earth we have calculated power of PV array in kWh. As we can see there is minor difference between the calculated and the actual power obtained. The power of PV array is calculated separately for each month, as the intensity of radiation falling on earth vary with each month.

\subsubsection{Electricity Bill Comparison}

The bar graph has been plotted to analyze the electricity bill with and without solar panel. As we can see there is noticeable difference with and without Solar panels. The electricity bill has been reduced to approximately half after the installation of solar panels.

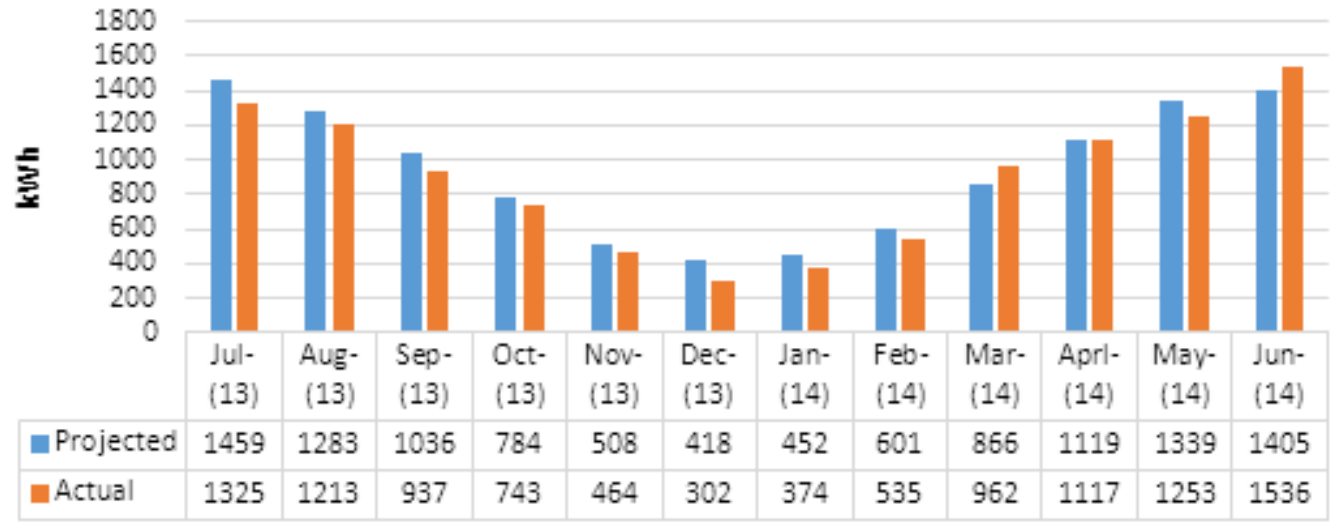

Figure 11. Monthly PV Production Chart 


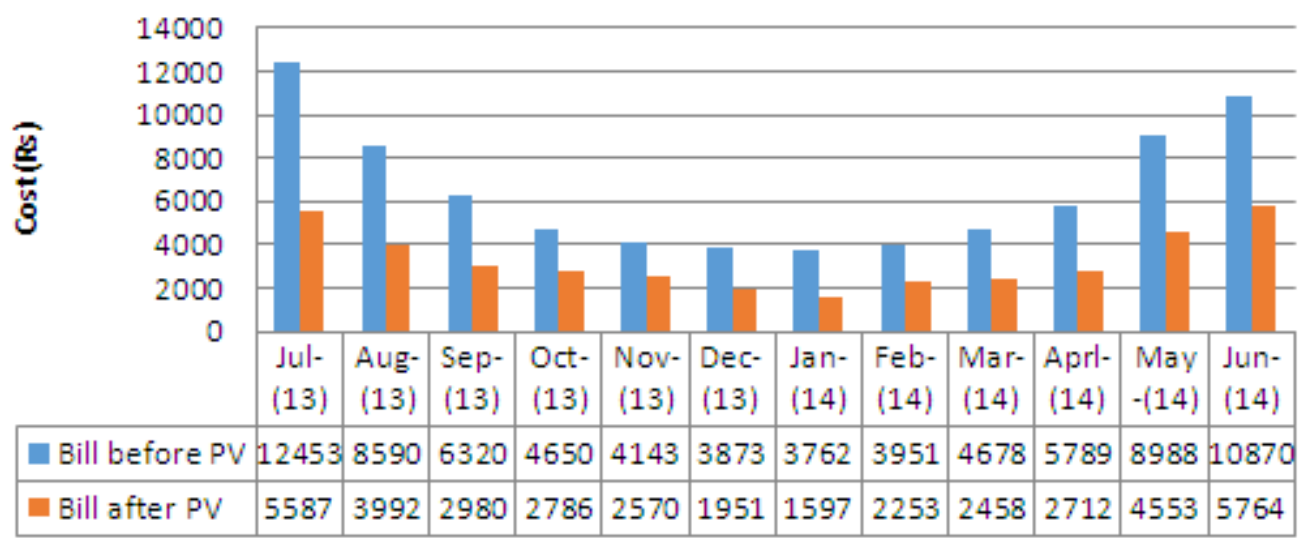

Figure 12. Electricity Bill-Before and After

\section{Model Design}

For testing the research project a model was developed. Tomeet with calculated $\mathrm{TDH}$, (for which primary design current and hydraulic energy is calculated), water is to be pumped to specific vertical height so overall vertical height of structure isselected to be 3.2 meters. The water pipe is lifted to that height. The $0.75 \mathrm{hp}$ centrifugal pump is connected to the tank via $25 \mathrm{~mm}$ pipe. However inverter is designed for 1000 watts. The water is pumped from 100 liters tank and then flows back to tank. The DC power is fed using three solar panel having total of 900 watts output power.

The specific design consists of followings main components.

1. Solar panel.

2. Centrifugal pump.

3. Soft Start Inverter.

4. Water tank.

5. Vertical Stand of $3.2 \mathrm{~m}$ height.

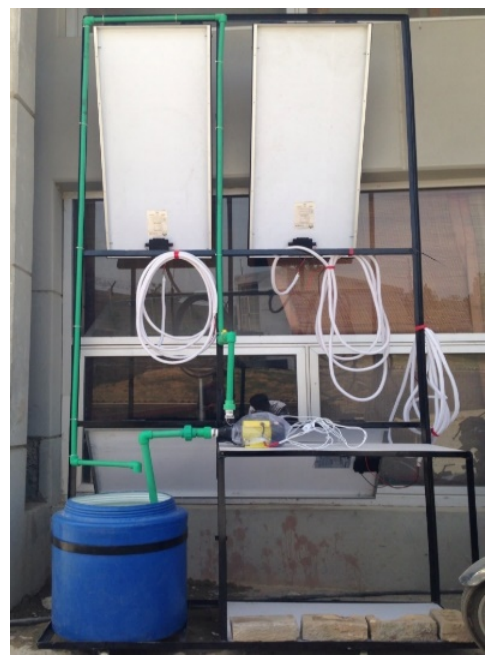

Figure 13. Working Model Structure

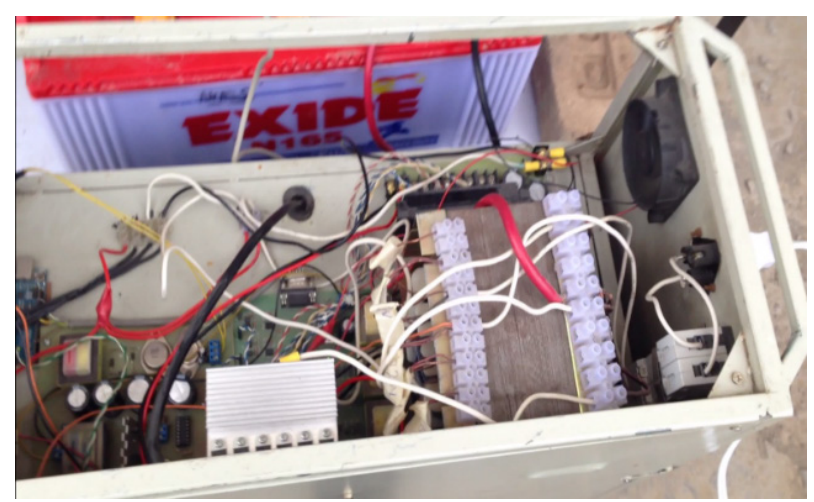

Figure 14. Soft Start Inverter Model

A small power supply was made to power VFD drive kit and controller using Oscillator SG3525 and 7805 and 7812 regulators to give fix and noise free uniform voltage. VFD kit was designed to use BJT's for fast switching while optocoupler were used for isolation of controller signal from circuit. Both the kit were designed and fabricated as shown in (Figure 15 and 16).

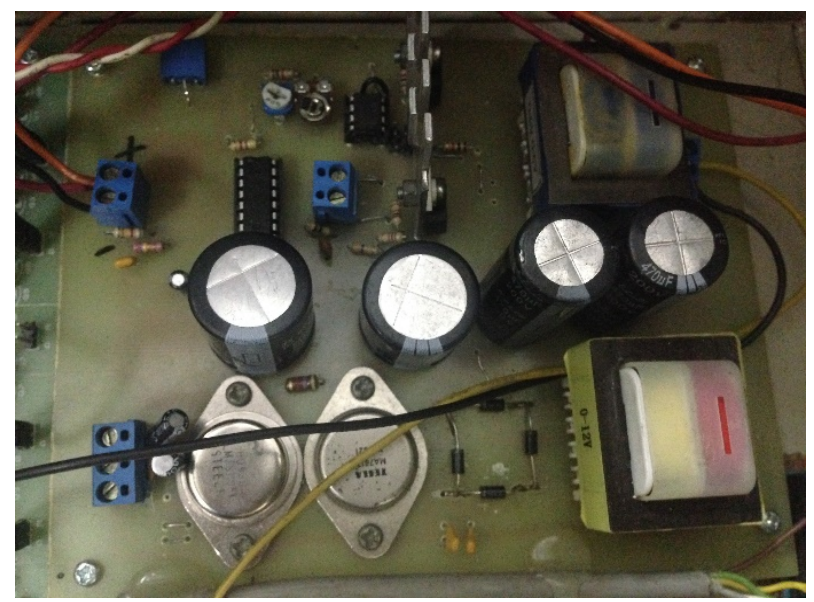

Figure 15. Oscillator and Power Supply Module 


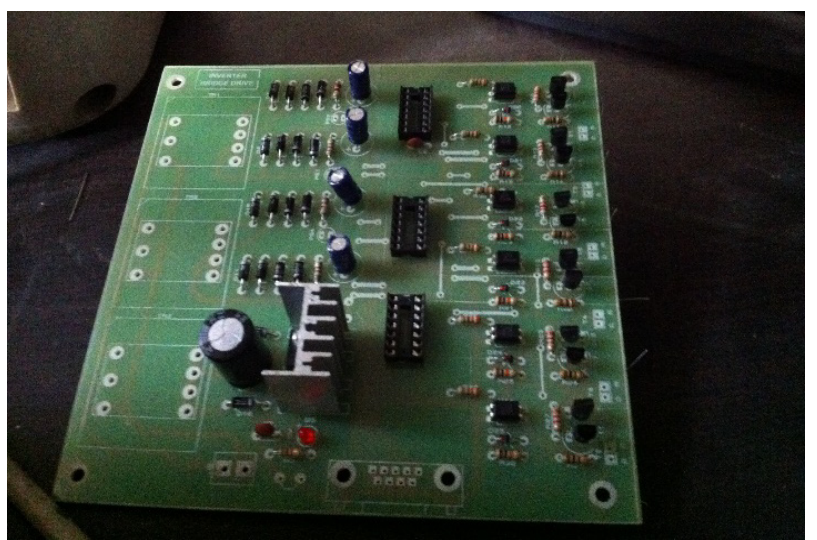

Figure 16. VFD Module Kit

Half H-Bridge was made using 75N75 mosfet. Each pair of mosfet gives 250 watt power. So six pairs were added parallel to meet up power requirement. The kit was designed and fabricated as shown in (figure 17).Step-up transformer of 1:20 was used as shown in (Figure 18).A 10Amps shunt type charge controller was designed to regulate voltage from $\mathrm{PV}$ array to charge storage and to prevent from overchargingas shown in (Figure 19). Full $\mathrm{H}$-Bridge was designed using IGBT to convert DC to AC using fast switching. The module was designed and fabricated as shown in (Figure 20).

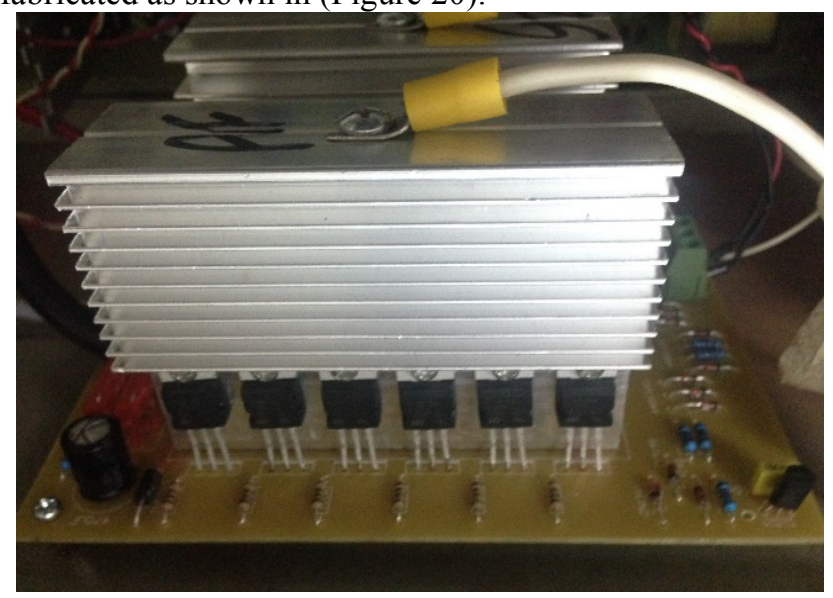

Figure 17. Half H-Bridge FET Module

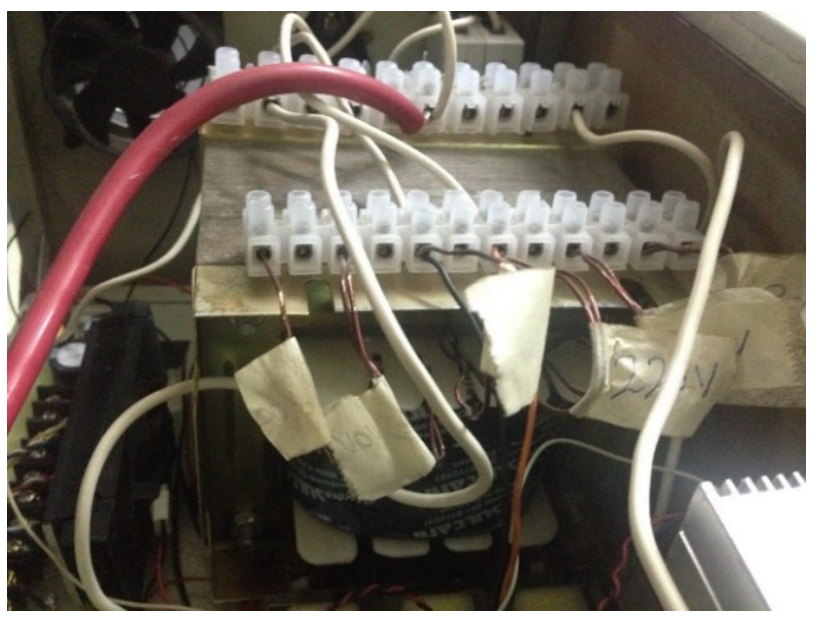

Figure 18. 1200Watt Step-up Transformer

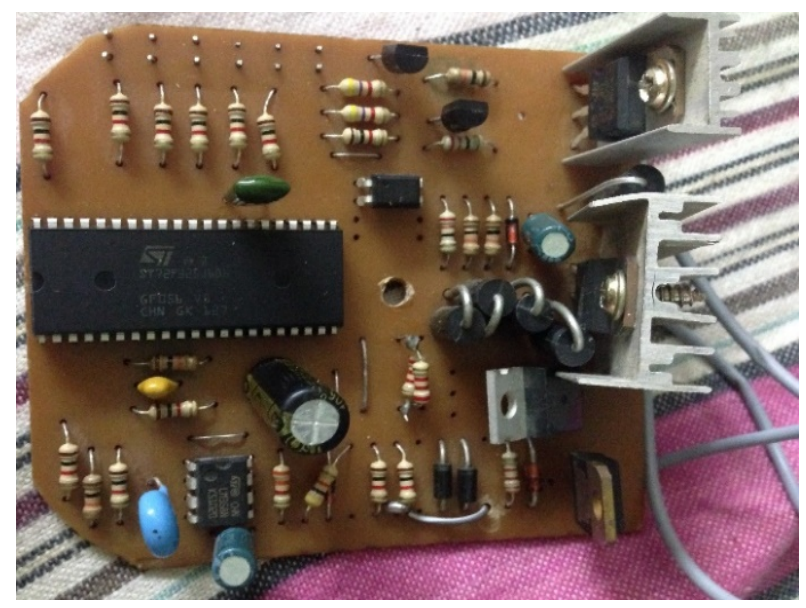

Figure 19. 10 Amps Charge Controller

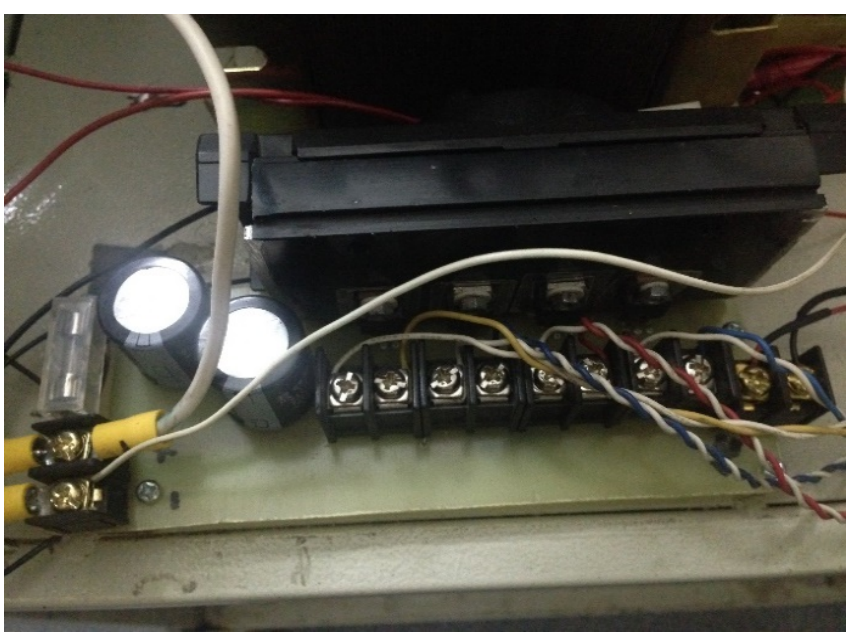

Figure 20. Full H-Bridge Module

\section{Conclusions}

The solar pumping model has been designed and implemented successfully. By making VFD soft start method we have reduced stall current. This unit can be controlled online by using Arduino Shield. It is programmed and easily controlled. The backup time can be increased by reducing the operating frequency of pump. This design and model can be used for submerged pumping as well as pumping of water at homes and at an industrial level.

\section{Future Recommendation}

Due to cost constraints controllers like 8051 or PIC $18 f 452$ be used. MPPT (Maximum Power Pointed Tracking) Charge controller, monocrystalline Solar panel instead of polycrystalline and Lithium Ion Battery can be used to decrease charge time and to increase backup time. 


\section{Nomenclature}

$\mathbf{A}_{\text {pv }}=$ Total solar panel Area $\left(\mathrm{m}^{2}\right)$

$\mathbf{H}=$ Annual average solar radiation on tilted panels (shadings not included)

TDH $=$ total dynamic head (meters)

$\mathbf{L}_{\mathbf{v}}=$ total vertical lift (meters)

$\boldsymbol{\lambda}_{\mathbf{F F}}=$ total friction and fittings losses (equivalent pipe length, in meters)

FOS=Factor of Safety

$\mathbf{Q}_{\text {Dr }}$ Total daily water requirement (liters/day)

$\boldsymbol{\eta}_{\text {pump }}=$ Pump efficiency fraction $(\times 100=$ percent $)$

$\mathbf{Q}_{\mathbf{P}}=$ Required Pump Rate (liters/hour)

$\mathbf{P}_{\text {pump }}=$ Rated Pump Power (Watts)

1/ $\mathbf{E}_{\mathbf{H y d}}=$ Reciprocal of the 'Energy Conversion factor' from (3)

$\mathbf{H}_{\mathbf{t}}=$ Mean monthly irradiation per day $\left(\mathrm{kWh} / \mathrm{m}^{2} /\right.$ day $)$

$\mathbf{I}_{\text {Desp }}=$ Preliminary design current (Ampere)

$\boldsymbol{\eta}_{\text {pump }}=$ Pump efficiency

$\mathbf{F}_{\mathbf{W L}}=$ Wire loss factor (fraction)

$\mathbf{V}_{\mathbf{n}=}=$ Preliminary Voltage

$\boldsymbol{\eta}_{\mathbf{p v}}=$ Efficiency of PV array

$\mathbf{A P V}=$ Total PV cell area [10]

- In winter irradiance is between in Islamabad 500-600 Watt $/ \mathrm{m}^{2}$

- In Summer irradiance is between in Islamabad 1000-1100 Watt $/ \mathrm{m}^{2}$

$\mathbf{C}_{\mathbf{p}}=$ is the amp-hour capacity at a $1 \mathrm{~A}$ discharge rate

$\mathbf{I}=$ is the discharge current in Amperes

$\mathbf{t}=$ is the discharge time, in hours

$\mathbf{n}=$ is the Peukert coefficient, typically 1.1 to 1.3

$\mathbf{P}_{\mathbf{d c}}=$ Power Delivered to Battery

$\mathbf{h}_{\mathbf{0}}=$ Time in hours

$\mathbf{E}_{\text {Irr }}=$ the daily average irradiance in $\left(\mathrm{W} / \mathrm{m}^{2}\right)$

$\mathbf{E}_{\boldsymbol{H} \boldsymbol{y d}}=$ Energy required for the project (Wh/day)

$\mathbf{E}_{\mathbf{d c}}=$ battery voltage

$\mathbf{E}=$ Energy (kWh)

$\mathbf{r}=$ solar panel yield (\%): ratio of one pv panel power (kWpeak) and area.

$\mathbf{P R}=$ Performance ratio, coefficient for losses (range between 0.5 and 0.9 )

\section{REFERENCES}

[1] Elgendy, Mohammed Ali, Bashar Zahawi, and David John Atkinson. Comparison of Directly Connected and Constant Voltage Controlled Photovoltaic Pumping Systems", IEEE Transactions on Sustainable Energy, 2010.

[2] Rohini Jyoti. Maximum Efficiency Operation of a Single Stage Inverter Fed Induction Motor PV Water Pumping System, First International Conference on Emerging Trends in Engineering and Technology,2008.

[3] Rashid, Muhammad H. Power Electronics: Circuits, Devices and Applications, $3^{\text {rd }}$ Edition, Prentice Hall,London,2003.

[4] Stephen J. Chapman, Electric Machinery Fundamentals, $4^{\text {th }}$ Edition, McGrawHill, Sydney, 2004.

[5] Eduard Muljadi, Roger Taylor. PV Water Pumping With A Peak Power Tracker Using A Simple Six Step Square Wave Inverter, National Renewable Energy Laboratory Golden, Colorado,1996

[6] Michael James Case*, Ernest Edward Denny. A Novel Approach to Photovoltaic Powered Water Pumping Design,13th International Power Electronics and Motion Control Conference,Poznań,2008.

[7] I. Compaore, J. Raharijaona, Y. Coulibaly, B. Dakyo. Effectiveness Evaluation of Photovoltaic Powered Water Pumping units in Sahelian area IEEE Electrical Power \& Energy Conference, Burkina Faso,2009.

[8] Azzedine Boutelhig, Yahia Bakelli. Comparative study on water Max A 64 DC pump performance based Photovoltaic Pumping System design to select the optimum heads in arid area,24th International Conference on Microelectronics (ICM),2012.

[9] Annual Solar Energy Output, Online available from:http://photovoltaic-software.com/PV-solar-energy-calc ulation.php

[10] Romana ,Q.Xinfa, I.Ahmad ,S.Sultan, Impact of Land forms on the Spatial Distribution of Extraterrestrial Solar Radiation in the Months of March and September, A Geographical Approach, Pakistan Journal of Meteorology, Pakistan, July 2012.

[11] How Lead Acid Batteries Work, Online available from: http://ecee.colorado.edu/ ecen4517/materials/Battery.pd 